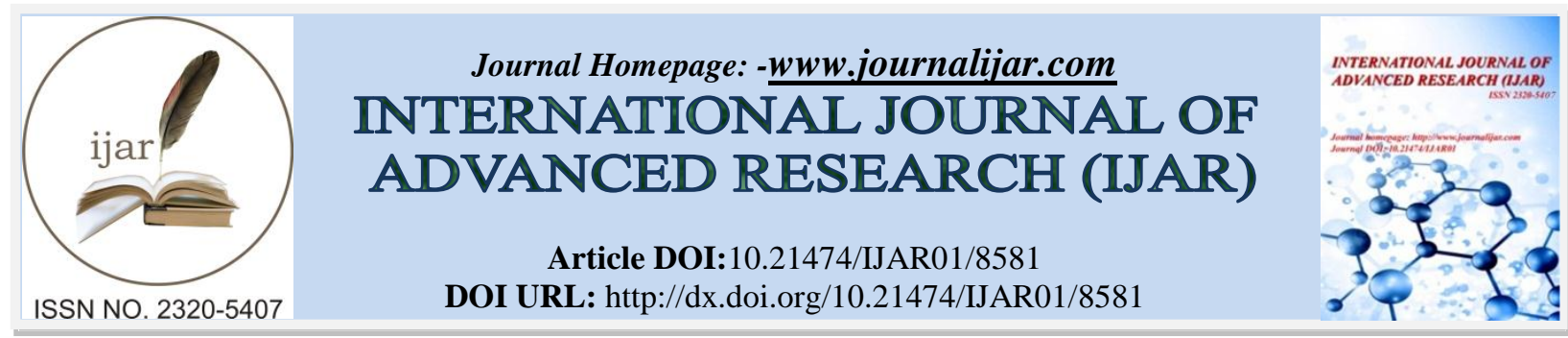

RESEARCH ARTICLE

\title{
A STUDY OF EVALUATION OF VARIOUS FACTORS OF INFERTILITY BY DIAGNOSTIC LAPAROSCOPY AT TERTIARY HOSPITAL.
}

\author{
Shazia Nisar ${ }^{1}$ And Shahzada Shahid Banday ${ }^{2}$. \\ 1. Senior Resident, Dept. of Obstetrics and Gynaecology SKIMS Soura, Srinagar. \\ 2. Senior Resident, Dept. of Neonatal \& Paediatric Surgery,Sher-I-Kashmir Institute Of Medical Sciences, Soura \\ Srinagar.
}

\section{Manuscript Info}

\section{Manuscript History}

Received: 14 December 2018

Final Accepted: 16 January 2019

Published: February 2019

\begin{abstract}
Background: Primary infertility is defined as inability to conceive where there is no previous pregnancy. Secondary infertility is one in which previous pregnancy has occurred regardless of the outcome. There are male as well as female factors in infertility.

Objective: To evaluate various factors of infertility by diagnostic laparoscopy at tertiary hospital.

Methods: A total of 70 patients including 50 primary and 20 secondary infertility females were included in this study. General examination, abdominal examination, vaginal examination ( $\mathrm{P} / \mathrm{V}$ as well as $\mathrm{P} / \mathrm{S})$ was done.

Results: Out of a total of 70 infertility patients, $50(71.4 \%)$ were primary infertility females and $20(28.57 \%)$ were secondary infertility females. Primary infertility was more in age group of 20-30 years while as secondary infertility was more in age group of 30-40 years.

Conclusion: In this study ovulatory causes were seen more in primary infertility while as tubal causes were seen in patients with secondary infertility.
\end{abstract}

Copy Right, IJAR, 2019,. All rights reserved.

\section{Introduction:-}

Infertility is defined as inability of a couple to conceive after one year of unprotected and regular intercourse. $85 \%$ of couples achieve pregnancy within this time without any assistance. Infertility affects 10-15\% of couples in reproductive age group ${ }^{1}$.

Primary infertility is defined as inability to conceive where there is no previous pregnancy. Secondary infertility is one in which previous pregnancy has occurred regardless of the outcome ${ }^{2}$. There are male as well as female factors in infertility. It is found that these female factors are more common in $\mathrm{Iran}^{3}$. It is estimated that secondary infertility affects 3 million couples worldwide ${ }^{4}$. The various factors of female infertility are:

(i) Anovulatory factors, (ii) Tubal factors, (iii) Endometriosis, (iv) Uterine factors, (v) cervical factors ${ }^{5}$.

Work up of a patient with female infertility starts with proper history and then thorough examination followed by series of investigations. History includes duration of infertility, history of intake of drugs, mode of previous delivery, any history of PPH in secondary infertility and comorbid conditions. Investigations start with baseline investigations, less invasive followed by more invasive and predictive investigations.one such investigation that is

Corresponding Author:-Shazia Nisar.

Address:-Senior Resident, Dept. of Obstetrics and Gynaecology SKIMS Soura, Srinagar. 
invasive but most accurate for predicting female infertility includes diagnostic laparoscopy. It is effective for evaluation of long term infertility ${ }^{6,7}$. The facility of diagnostic laparoscopy is readily available at Tertiary centres and our hospital being one such unit which enabled us to choose this topic as our study.

It has been found that important causes of female infertility in developing includes, PID, postabortal and post puerperal infections and tuberculosis ${ }^{8}$.

When we choose diagnostic laparoscopy as method of investigation in female infertility we can see whole of the pelvis including condition of tubes, ovaries, uterus and at the same time we can reach at the diagnosis of PIH, endometriosis, Tuberculosis ${ }^{9,10}$.

Among the various factors of female infertility as mentioned above predominant factors are tubo-ovarian factors. The main utility of diagnostic laparoscopy is that it not only helps to detect the external condition of tubes but at the same time we can check the patency of tubes as well ${ }^{11}$.

Although patency of tubes can be checked by hysterosalpingography but false positive rate is $21 \%$ which is not a case with diagnostic laparoscopy ${ }^{12}$.

\section{Objective:-}

To evaluate various factors of infertility by diagnostic laparoscopy at tertiary hospital.

\section{Methodology:-}

This was an Observational study carried in our tertiary hospital Department of Obstetrics and Gynaecology at SKIMS Soura. It was done over a period of one year November 2017-December 2018. Total of 70 patients were included in our study. Out of these 70 patients, 50 patients were of primary infertility and 20 patients were of secondary infertility. Detailed history was taken from patients as below: (i) Name, (ii) Age, (iii) Nature of infertility, (iv) Duration of infertility, (v) Menstrual history, (vi) Past obstetric history in case of secondary infertility, (vii) Gynaecological history, (viii) Medical history, (ix) Surgical history, (x) Personal history, (xi) Sexual history, (xii) History of any treatment received for infertility.

Examination was done as General examination, abdominal examination, vaginal examination (P/V as well as $\mathrm{P} / \mathrm{S})$

\section{Investigation:-}

(A) CBC; (B) TLC; (C) DLC; (D) ESR; (E) Routine U/E; (F) Chest X-Ray; (G) Mantoux; (H) USG; (I) Husband Semen Analysis; (J) Hormonal Profile FSH, LH, TSH, Progesterone.

A detailed consent was taken for invasive procedure of laparoscopy. After obtaining consent patients were admitted and preanesthetic checkup was done. Patients were dated for laparoscopy in their premenstrual period. During this procedure whole of pelvis was visualised including peritoneum for any endometriotic deposits, adhesions, ovaries for their shape, size and evidence of ovulation. Tubes for their motility, peritubal adhesions, Uterus for any fibroid, round ligaments, uterosacral ligaments, uterovesical pouch and POD for any fluid. Besides this patency of tubes was tested by injecting methylene blue dye through OS and detecting it's spillage through fimbria end of tubes. Dilatation and curettage was also done and endometrium was send for histopathological examination.

\section{Inclusion Criteria:-}

Women within reproductive age group with both primary as well as secondary infertility.

\section{Exclusion Criteria:-}

1. Patients with male infertility

2. Patients with COPD, extreme obesity or other comorbidity that contraindicate laparoscopy.

3. Patients with premature ovarian failure

4. Patients with tubectomy and IUD'S

5. Patients with known PID 


\section{Results:-}

1. Total number of patients with infertility $=70$

2. Those with primary infertility $=50(71.4 \%)$

3. Those with secondary infertility $=20(28.57 \%$

Table 1:-Distribution of Age, duration of infertility and residence

\begin{tabular}{|c|c|c|c|}
\hline \multicolumn{2}{|c|}{} & Primary infertility & Secondary infertility \\
\hline \multirow{3}{*}{ Age in years } & $10-20$ & 0 & 0 \\
\cline { 2 - 4 } & $20-30$ & $29(58 \%)$ & $8(40 \%)$ \\
\cline { 2 - 4 } & $30-40$ & $21(42 \%)$ & $12(60 \%)$ \\
\hline \multirow{3}{*}{ Duration in Years } & $2-3$ & $18(30 \%)$ & $2(10 \%)$ \\
\cline { 2 - 4 } & $4-6$ & $20(40 \%)$ & $4(20 \%)$ \\
\cline { 2 - 4 } & $7-8$ & $12(24 \%)$ & $14(70 \%)$ \\
\hline \multirow{2}{*}{ Residence } & Rural & $18(36 \%)$ & $5(25 \%)$ \\
\cline { 2 - 4 } & Urban & $32(64 \%)$ & $15(75 \%)$ \\
\hline
\end{tabular}

1. Thus primary infertility was more in age group of 20-30 years

2. Secondary infertility was more in age group of 30-40 years

3. Thus primary infertility was more of 4-6 years of duration

4. Secondary infertility was more of 7-8 years duration.

5. Primary infertility (64\%) and in secondary infertility $75 \%$ belonged to urban areas

Table 2:-Distribution of patients according to various factors of Infertility.

\begin{tabular}{|l|c|c|c|}
\hline \multicolumn{1}{|c|}{ Finding on laparoscopy } & $\begin{array}{c}\text { Primary } \\
\text { infertility }\end{array}$ & Secondary infertility & Total \\
\hline Tubal block & $3(6 \%)$ & $8(40 \%)$ & $11(15.7 \%)$ \\
\hline PCOD & $13(26 \%)$ & 0 & $13(18.8 \%)$ \\
\hline Uterine anomalies & $2(4 \%)$ & 0 & $2(2.8 \%)$ \\
\hline Uterine fibroid & $3(15 \%)$ & $1(2 \%)$ & $4(5.7 \%)$ \\
\hline Peritubal and periovarian adhesions & $2(4 \%)$ & $3(15 \%)$ & $9(12.8 \%)$ \\
\hline Endometriotic deposits & $9(18 \%)$ & $2(10 \%)$ & $11(15.7 \%)$ \\
\hline PID & $1(2 \%)$ & $4(20 \%)$ & $8(11.4 \%)$ \\
\hline No cause detected & $17(34 \%)$ & $2(10 \%)$ & $19(27.14 \%)$ \\
\hline
\end{tabular}

\section{Discussion:-}

Infertility is most common issue in modern society. It affects approximately $15 \%$ of couples. Among various factors of infertility the most important determining factor is age of female. It has found that after one year of unprotected and regular intercourse if a couple fails to achieve pregnancy that is an indication to investigate the couple. But if the age of female is above 35 years then she should be subjected to early investigations [NICE recommendation ${ }^{12}$.

While as there is no universally accepted Definition of advanced reproductive, yet 35 year is considered as limit in fertility terms(American society of reproductive medicine 2006) ${ }^{12}$.

In present study $58 \%$ of patients with primary infertility had mean age of 20-30years while in secondary infertility $60 \%$ of patients had mean age of 30-40 years while Talib reported mean age of 22.1 years in primary infertility and 29.4 years in secondary infertility ${ }^{13}$

In our study Mean duration of infertility was; $40 \%$ of patients in primary infertility had mean duration of 2-3 years and $70 \%$ of patients with secondary infertility had mean duration of 7-8 years. Similar results were obtained from Lahore where in results of $58 \%$ of patients in primary infertility of $2-5$ year duration and $77 \%$ of patients with secondary infertility had duration of over 5 years ${ }^{14}$.

If we see distribution of patients according to residence we can see $36 \%$ of patients with primary infertility belonged to rural areas and $64 \%$ of them belonged to urban areas. In case of secondary infertility $25 \%$ belonged to rural and $75 \%$ belonged to urban areas. Thus majority of patients were from urban areas. 
While doing laparoscopy we encountered with various pathological findings. All those patients that presented with symptoms of pain, dysparenia, irregular periods were subjected to early work up ${ }^{15}$. Laparoscopy was normal in $27.14 \%$ of patients, among this $34 \%$ of patients were of primary infertility and $10 \%$ were of secondary infertility. Abnormal finding were as below;

\section{Laparoscopy with dye injection was done to detect tubal block:-}

Tubal block was seen in $40 \%$ of patients with secondary infertility and $6 \%$ of patients with primary infertility. This closely resembles with various studies in which primary infertility was seen in $15-20 \%$ of patients with tubal block and secondary infertility in $40 \%$ of patients ${ }^{16}$, increased tubal block was seen in secondary infertility.

PID represents $11.4 \%$ of total cases, $20 \%$ in secondary infertility and $2 \%$ in primary infertility. It is found one episode of PID causes tubal block in $12 \%$, second episode in $35 \%$ and third $75 \%$ of patients. PID and tubal block was more in secondary infertility ${ }^{17}$. Same results as from Peshawar.

Among ovulatory causes PCOD is main reason for Anovulation $16-33 \%{ }^{18}$. Anovulation itself accounts for $30-40 \%$ of cases of infertility. In present study PCOD was seen in $18.8 \%$ of patients, this closely resembles with the above figure, $26 \%$ in those with primary infertility and none in case of secondary infertility.

Endometriosis may lead to infertility in females. For diagnosing and treatment of endometriosis confirmation by laparoscopy is gold standard ${ }^{19}$. In present study endometriosis was seen in $15.7 \%$ of patients, $18 \%$ of those with primary infertility and $10 \%$ of those with secondary infertility. Incidence of endometriosis in study conducted by Mahmoud was $13.6 \%$ that resembles in our study.

Uterine factors contribute to 5-10\% of cases of infertility. In present study uterine anomalies accounted for $2.8 \%$ of cases. Uterine fibroid was seen in $5.7 \%$ of patients, this resembles to studies of Khaula from Lahore that show frequency of fibroid as $6 \%$.

In my study main causes of secondary infertility are tubal block, PID and peritubal, periovarian adhesions while as the main causes of primary infertility were PCOD, fibriod, endometriosis and unknown.

\section{Conclusion:-}

Laparoscopy is considered as gold standard for evaluating cause of infertility. Not only this, various therapeutic measures can be done simultaneously. In my study ovulatory causes were seen more in primary infertility while as tubal causes were seen in patients with secondary infertility. In patients with infertility who present with other symptoms and also those who are above 35 years of age should be subjected to early laparoscopy evaluation.

\section{Bibliography:-}

1. Janathan S. Berek MD. Novak's Gynaecology-MMSC, Thirteenth Edition. Infertility; 974.

2. Jeffcoats Principles of Gynaecology - International Edition - 5th Edition- Infertility and Assisted Reproductive technology, Page 644.

3. Aflatoonian A, Seyedhassani SM, Tabibnejad N. The epidemiological and etiological aspects of infertility in Yazd province of Iran .Iranian J Reprod Med 2009; 7: 117-22.

4. Kliger BE. Evaluation, therapy, and outcome in 493 infertile couples. Fertil and Steril. 1984; 41(1): 40-46.

5. Jose Miller AB, Boyden JW, Frey KA. Infertility. Am Fan Physician 2007; 75: 849-56.

6. Godinjak Z, Idrizbegovic E. Should Diagnostic hysteroscopy be a routine procedure during diagnostic laparoscopy in infertile women? Bosn J Basic Med Sci 2008; 8: 44-7.

7. Fartum M, Laufer N, Simon A. Investigations of infertile couple: Should diagnostic laparoscopy be performed after normal hysterosalpingography in treating infertility suspected to be of unknown origin? Hum Reprod 2002; 17: 1-3.

8. Rehana R, Majid SS. Aetiological factors of infertility. J Postgraduate Med Inst 2004; 18: 166-71.

9. Mahmood S. An audit of diagnostic laparoscopies for infertility. J Surg Pak 2003; 8: 8-10.

10. Sajida P, Majidah K. Role of combined diagnostic laparoscopy and simultaneous diagnostic hysteroscopy for evaluation of female subfertility factors. J Surg Pak 2010; 15: 44-7. 
11. Tanahatoe SJ, Hompes PG, Lambalk CB. Investigations of infertile couple should diagnostic laparoscopy be performed in the infertility work-up program in patients undergoing intrauterine insemination. Hum Reprod 2003; 18: 8-11.

12. Maheshwari A, Hamilton M, Battacharya S. Effect of female age on the diagnostic categories of infertility. Hum Reprod 2008; 23: 538-42.

13. Talib W, IKram M, Maimoona H, Saeed M. Infertile female: laparoscopic evaluation. Professional Med J 2007; 14: 562-6.

14. Ashraf V, Baqai SM. Laparoscopy: Diagnostic role in infertility. Professional Med J 2005; 12: 74-9.

15. Millingos S, Protopapas A, Kallipolitis G, Drakakis P, Makrigiannakis A, Liapi, et al. Laparoscopic evaluation of infertile patients with chronic Pelvic pain. Reprod Biomed Online 2006; 12: 347-53.

16. Khaula K. Role of diagnostic laparoscopy in evaluation of female subfertility Serv Inst Med SCI 2005; 3: 31-4.

17. Talat N, Lubna H, Gulmeen, Farrah N, Shahida S. Laparoscopic evaluation in infertility. J Coll Physicians Surg Pak 2009; 19: 704-7.

18. Enda McVeigh. Polycystic ovarian syndrome. In: Barker PN, Lensley DM, editors. Obstetric and Gynaecology: an evidence based text for MRCOG London: Oxford University Press; 2004: P-588-93.

19. Farook SM. Laparoscopic evaluation of chronic Pelvic pain. Am KE Med Coll 1998; 4: 21-4.

20. Khaula K, Rehana MM. Various factors for infertility in infertility clinic, Gynae Unit-1, Services hospital, Lahore. Ann King Edward Med Uni 2005; 11(4): 427-31. 